http://jmscr.igmpublication.org/home/ ISSN (e)-2347-176x ISSN (p) 2455-0450

crossref DOI: https://dx.doi.org/10.18535/jmscr/v8i11.98

Journal Of Medical Science And Clinical Research

\title{
Comparative Study of Epidural Injection of 0.5\% Bupivacaine with Buprenorphine and $0.5 \%$ Bupivacaine with Fentanyl for Lower Limb Surgeries
}

\author{
Authors \\ Dr Bala Muralikrishna Muppala ${ }^{1 *}$, Dr Konduru Sindhura ${ }^{2}$, \\ Dr Kalyan Chakravarthy $\mathbf{P}^{\mathbf{3}}$ \\ ${ }^{1}$ Post Graduate, Department of Anaesthesiology, GEMS \\ ${ }^{2}$ Senior Resident, Department of Anaesthesiology, GEMS \\ ${ }^{3}$ Professor\& HOD, Department of Anaesthesiology, GEMS \\ *Corresponding Author \\ Dr Bala Muralikrishna Muppala
}

\begin{abstract}
Background: Epidural anaesthesia is one of the best accepted techniques for lower limb surgeries as it provides good sensory and motor block and decreases adverse physiologic responses to surgery such as autonomic hyperactivity, cardiovascular stress, increased metabolic rate, pulmonary dysfunction and immune system dysfunction. In present day practice of anaesthesiology, bupivacaine is the most commonly used drug for regional anaesthesia. To improve quality of analgesia and to prolong duration of action many adjuvants have been tried.

Aim: This study compared 0.5\% bupivacaine with buprenorphine and $0.5 \%$ bupivacaine with fentanyl in lower limb surgeries under epidural anaesthesia.

Materials \& Methods: A randomized prospective observational study includes 60 patients of ASA I\&II aged 18-60 years, posted for elective lower limb surgeries under epidural anaesthesia. Patients were randomly divided in to two groups of 30 each. Group A received

$0.5 \%$ Bupivacaine $15 \mathrm{ml}(75 \mathrm{mg})+0.5 \mathrm{~m} \mathrm{l}(150 \mathrm{mcg})$ Buprenorphine $+0.5 \mathrm{ml}$ normal saline made to a total of $16 \mathrm{ml}$. Group B received 0.5\% Bupivacaine+ $1 \mathrm{ml}(50 \mathrm{mcg})$ Fentanyl. vitals were monitored. Onset of sensory and motor blockade, quality and duration of postoperative analgesia, side effects were recorded.

Results: The onset of sensory blockade and motor blockade was faster in group B compared to group A. Duration of analgesia was significantly longer in Group A. The incidence of Nausea and vomiting was more in group A. No significant haemodynamic changes were observed in both the groups.

Conclusion: Epidural injection of $0.5 \%$ bupivacaine with $150 \mathrm{mcg}$ buprenorphine is better in providing prolonged satisfactory postoperative analgesia as compared to Fentanyl.

Keywords: Epidural anaesthesia, bupivacaine, buprenorphine, fentanyl.
\end{abstract}

\section{Introduction}

Regional anaesthesia is a preferred technique for lower extremity surgeries. ${ }^{[1]}$ Intrathecal anaesthesia and epidural anaesthesia (EA) are the most popular regional anaesthesia techniques used for lower limb orthopaedic surgeries. But spinal anaesthesia has few limitations like, shorter 
duration of post-operative analgesia and postdural puncture headache (PDPH). ${ }^{[2]}$

EA is becoming one of the most useful and versatile procedures in modern anaesthesiology, giving the clinician the opportunity to provide both anaesthesia and analgesia. The advantages of EA are providing effective surgical anaesthesia and can meet the extended duration of surgical needs, prolonged post-operative analgesia, reduces the incidence of hemodynamic changes as a result of sympathetic blockade as it can produce segmental anaesthesia unlike subarachnoid block anaesthesia. ${ }^{[2,3]}$

Bupivacaine is the most commonly used drug in epidural anaesthesia. ${ }^{[4]}$ A local anaesthetic and an opioid combination can provide superior analgesia during perioperative and postoperative period. ${ }^{[5]}$ Buprenorphine is a mu-receptor partial agonist and antagonist. ${ }^{[5]}$ Fentanyl is a phenylpiperidinederivative synthetic opioid agonist. ${ }^{[6,7,8]}$ The present study was designed to compare between epidural bupivacaine combined with buprenorphine vs fentanyl for lower limb surgeries.

\section{Materials and Method}

A randomized observational prospective study was conducted at Great Eastern Medical School \& Hospital, Ragolu. After Ethical committee clearance and informed consent, a total of 60 patients of either sex aged between 18-60 years belonging to ASA I \& II scheduled for elective lower limb surgeries were randomly selected.

\section{Exclusion Criteria}

$>$ Pregnant women

> Patients with H/o Cardio-Respiratory disorders

$>$ Patients with Hepatic and Renal diseases

$>$ Patients with H/o convulsions \& neurological deficits

$>$ Patients with Spinal deformities \& Psychiatric diseases

> Patients with ASA Grade III \& above

$>$ Patients contra-indicated for epidural anaesthesia
All patients undergone thorough pre-anaesthetic evaluation a day before surgery and explained in detail regarding the anaesthetic procedure. Patients were educated about Verbal numerical scale for assessment of pain. Written informed consent was obtained. Patients were advised nil oral for 6 hours prior to surgery. Patients were shifted to operating room on the day of surgery, connected to multiparameter monitor and baseline heart rate, NIBP and Spo2 was recorded. An 18G IV cannula was inserted and $10 \mathrm{ml} / \mathrm{kg}$ of $0.9 \%$ saline was infused over the 15 minutes preceding the epidural anaesthesia. In sitting position, L2-L3 interspace was identified. Under strict aseptic precautions, after injecting local anaesthetic solution, epidural space was identified using $18 \mathrm{~g}$ Tuohy needle by LOR technique to air, epidural catheter was inserted $3 \mathrm{~cm}$ inside epidural space and secured in place, continuous monitoring was done. A test dose of $3 \mathrm{ml}$ of $2 \%$ lignocaine with adrenaline $(1: 2,00,000)$ was given to rule out intravascular or intrathecal placement. 5 minutes after test dose, in the absence of any adverse sequelae, $16 \mathrm{ml}$ of study drug was injected depending on patient study group through epidural catheter and patient were made to lie supine. After adequate blockade (T10) patient was repositioned based on surgical requirements.

Patients were divided into two groups:

Group A received $-0.5 \%$ Bupivacaine $15 \mathrm{ml}$ $(75 \mathrm{mg})+0.5 \mathrm{ml}(150 \mathrm{ug})$ Buprenorphine (preservative free) $+0.5 \mathrm{ml}$ sterile normal saline. of total $16 \mathrm{ml}$.

Group B received - $0.5 \%$ Bupivacaine $15 \mathrm{ml}$ $(75 \mathrm{mg})+1 \mathrm{ml}$ (50ug) Fentanyl (preservative free). All the patients were given Oxygen @ 5L/min through face mask. No intravenous analgesics or opioids were administered during the surgery. Assessment of block characteristics were done with the patient in supine position after completion of the epidural injection. The time at which the study drug injection completed was considered as zero $(t=0)$. The onset of block time and the time for maximum sensory block and the maximum level of sensory and motor block were 
recorded. Sensory blockade was assessed by a short bevelled 22gauge needle and was tested in the mid clavicular line on either side.

Motor blockade was assessed using modified Bromage scale.

0 - no motor blockade

1- Inability to raise extended leg (just able to move knee)

2 - Inability to flex the knee (able to move the foot)

3 - Inability to flex ankle joint (unable to move knee or foot)

Vital parameters such as $\mathrm{HR}, \mathrm{NIBP}, \mathrm{RR}$, and $\mathrm{SPO}_{2}$ were continuously monitored for every $5 \mathrm{~min}$ for first $15 \mathrm{~min}$ and every $15 \mathrm{~min}$ thereafter till surgery completed and every half an hour in the postoperative period for 2 hours.

Incidence of complications like nausea, vomiting, bradycardia, hypotension, respiratory depression and pruritus were noted and treated accordingly.

Hypotension is defined as reduction in systolic blood pressure more than $30 \%$ from basaline or < $90 \mathrm{mmHg}$ and is treated with bolus of intravenous fluids and if needed injection mephenteramine 3 $\mathrm{mg}$ (I.V) was given in incremental doses. Bradycardia ( $<60$ beats/min) was treated with injection Atropine $0.6 \mathrm{mg}$ (IV).

Duration of Motor Block: is the time taken from the time of injection till the patient attains complete motor recovery (Bromage 0 ).

Duration of Analgesia: is the time taken from the time of injection till the patient complains of pain at the site of surgery.

Postoperatively, Duration of post-operative analgesia, Quality of post-operative analgesia (VNS), the need for rescue analgesic supplementation, Episodes of postoperative side effects were noted and treated.

\section{Statistical Analysis}

All the data was pooled in excel sheet and quantitative data were presented in mean and standard deviation and analysed by using student t-test. $\mathrm{P}$ value of $<0.05$ significant $<0.01-$ Highly significant.

\section{Results}

Both the groups were comparable in terms of demographic characteristics like age, weight and duration of surgery and preoperative vital parameters.

\begin{tabular}{|l|c|c|c|}
\hline Variables & Group A & Group B & p-value \\
\hline Age(yrs) & $42.3 \pm 10.5$ & $40.4 \pm 12.4$ & 0.43 \\
\hline Weight(kgs) & $56.7 \pm 8.4$ & $57.1 \pm 1.1$ & 0.49 \\
\hline Sex- male & 19 & 18 & \\
Female & 11 & 12 & \\
\hline
\end{tabular}

\section{Block Characteristics}

\begin{tabular}{|l|c|c|c|}
\hline Parameters & Group A & Group B & p- value \\
\hline $\begin{array}{l}\text { Onset of } \\
\text { analgesia (T12) }\end{array}$ & $7.56 \pm 3.11$ & $6.66 \pm 2.44$ & $>0.05$ \\
\hline $\begin{array}{l}\text { Time to achieve } \\
\text { complete motor } \\
\text { block }\end{array}$ & $18.9 \pm 3.55$ & $18.63 \pm 3.25$ & $>0.05$ \\
\hline $\begin{array}{l}\text { Duration of } \\
\text { analgesia }\end{array}$ & $766.6 \pm 169.67$ & $471 \pm 148.68$ & $<\mathbf{0 . 0 5}(\mathbf{S})$ \\
\hline
\end{tabular}

\section{Side Effects}

\begin{tabular}{|l|c|c|}
\hline Parameters & Group A & Group B \\
\hline Nausea & 9 & 2 \\
\hline Vomiting & 3 & - \\
\hline Pruritis & - & 10 \\
\hline Hypotension & - & - \\
\hline
\end{tabular}

\section{Discussion}

The operative pain is more severe after surgery and thereafter gradually diminishes over the next 24 hours. The pain in the postoperative period demands relief not only on humanitarian ground but also to reduce physical morbidity following the operation. ${ }^{[9]}$ In postoperative period when the effect of the anaesthetic disappears, the tissue injury persists and pain producing substances which are liberated during the operation greatly reduce the normally high threshold of the nociceptors, so that innocuous stimulation produces pain. Moreover the cut ends of axons further contribute to nociception. A wide range of options exist to combat pain both pharmacologically and non-pharmacologically.

However, despite the increasing complex armamentarium that we have at our disposal, the satisfactory alleviation of pain remains difficult goal. Thus, the extent of our pharmacological alternatives is rather a reflection of our constant 
efforts to obtain more effective and safer analgesics. ${ }^{[10]}$

Epidural anaesthesia is superior to Spinal as the desired block levels can be achieved without significant haemodynamic disturbances and topup doses of anaesthetics \& analgesics can be given. In modern anaesthesia practice Epidural anaesthesia is widely being used especially in patients undergoing surgical procedures involving lower parts of the body. To fulfil this demand, there is a need for local anaesthetic with desirable properties like longer duration of sensory blockade and shorter duration of motor blockade. ${ }^{[10]}$

Traditionally epidural bupivacaine was used for post-operative analgesia. The epidural bupivacaine $0.5 \%$ causes motor, sensory and sympathetic blockade, $0.25 \%$ causes sensory and autonomic blockade and $0.125 \%$ causes autonomic blockade only. Epidural and intrathecal opioids are today being used for intraoperative and postoperative analgesia.

This study was done to evaluate sensory and motor blocking properties, quality and duration of analgesia using buprenorphine and fentanyl in combination with bupivacaine. We chose 3 $\mathrm{mcg} / \mathrm{kg}$ of Buprenorphine and fixed the dose as $150 \mathrm{mcg}$ for our study, based on previous studies done by Mamthaagarval et al, ${ }^{[11]}$ Ichiishi $\mathrm{N}$ et al ${ }^{[12]}$ and Bhargava et al. ${ }^{[13]}$ fentanyl dose of $50 \mathrm{mcg}$ based on study done by Suraj Dhalae et al. ${ }^{[14]}$

\section{Following parameters were studied:}
1) Sensory and motor blockade intraoperatively

2) Quality and duration of Postoperative analgesia.

3) Changes in hemodynamic and respiratory parameters.

4) The side effects like nausea and vomiting, respiratory depression, urinary retention, pruritus and others if any.

Both the groups were comparable in terms of Demographic profile.

Onset of sensory blockade is taken as the time from the completion of the injection of the study drug till the patient does not feel the pinprick at T10 dependent side. The time of onset of sensory block in our study was Group-A 7.53min and Group-B 6.60min which is statistically insignificant which is similar to the study done by Zenz M, Pipenbrock S. ${ }^{[15]}$ They compared epidural Buprenorphine and epidural morphine for postoperative pain relief. Buprenorphine group produced analgesia with short latency $6.8 \mathrm{~min}$. This is close to our observation of $7.53 \mathrm{~min}$.High lipid solubility and high potency may explain the faster onset of pain relief in buprenorphine group. Boas RA et al.in their study on clinical actions of Fentanyl and Buprenorphine and the significance of receptor binding. Buprenorphine showed slow receptor association (30 $\mathrm{min})$, but with high affinity to multiple sites from which dissociation was very slow ( $\left.\mathrm{t}_{1 / 2} 166 \mathrm{~min}\right)$ and incomplete $(50 \%$ binding after $1 \mathrm{hr}$ ). This contrasted with the receptor binding of fentanyl, which achieved rapid equilibrium (within $10 \mathrm{~min}$ ) and dissociated equally rapidly $\left(\mathrm{t}_{1 / 2} 6.8 \mathrm{~min}\right)$ and completely $(100 \%$ by $1 \mathrm{hr}$ ). They concluded that competitive displacement showed buprenorphine displacement of fentanyl binding was concentration and time dependent over ranges encountered in clinical use, but buprenorphine binding was displaced with only very high concentrations of other opioids. ${ }^{[16]}$

Motor Blockade: Onset of motor blockade is taken from the completion of the injection of study drug till the patient develops modified Bromage scale grade- 1 motor blockade. Time for maximum motor blockade is defined as the time from the completion of the injection of the study drug to the maximum motor blockade attained.

The mean time to achieve complete motor blockade was 18.9 min in group A and 18.63min in group B. which was statically insignificant. But in a study done by Suraj Dhale ${ }^{[14]}$ and Vaishali Shelgaonkar, in 2000. They studied different doses of epidural fentanyl $(25 \mu \mathrm{g}, 50 \mu \mathrm{g}, 75 \mu \mathrm{g})$ with $0.5 \%$ bupivacaine for perioperative analgesia where mean onset of motor blockade was $26.13 \pm$ $1.80 \mathrm{~min}$. 
Duration of analgesia is taken from the time of injection till the patient complains of pain at the site of surgery. Time at which, patients complained of pain more than 5 and above on the verbal numerical scale was noted. That point was taken as the end of fair analgesia and at that point, top-up doses were given based on requirement.

In our study, the duration of analgesia in group A was $766 \mathrm{~min}$ which was significantly longer compared to group B of 471 min.

In a comparative study between epidural buprenorphine and epidural Ketamine for postoperative pain relief done by D.Kumar, N. Dev and N.Gupta ${ }^{[17]}$ found that $0.15 \mathrm{mg}$ Buprenorphine with $10 \mathrm{ml}$ of $0.9 \%$ saline had longer duration of action 13.1hours (range 8-12 hours) compared to $10 \mathrm{mg}$ of Ketamine with $10 \mathrm{ml}$ of $0.9 \%$ saline, which had mean duration of 5.2 hours. Our results are correlating with this study. Longer duration of action and analgesia of epidural buprenorphine can be explained by its high affinity for spinal receptors. Smaller doses of buprenorphine produce a high concentration of the drug at spinal receptors. Higher lipid solubility of buprenorphine favors its diffusion in to spinal cord. The diffusion from the spinal cord in to the blood stream is slow and does not approach the bulbar Centers. Hence high lipid solubility, strong opiate receptor binding and intense and prolonged activity was responsible for longer duration of action.

The objective parameters of analgesia like mean arterial pressure(MAP) and heart rate (HR) were compared, before giving the drug and after giving the drug at intervals for every $5 \mathrm{~min}$ for first $15 \mathrm{~min}$ and every $15 \mathrm{~min}$ throughout during intraoperative period and every half an hour in the post-operative period for 2 hours.

The reduction in MAP was statistically insignificant in both groups. In group A, MAP from base line $95.13 \mathrm{mmHg}$ decreased to $84.8 \mathrm{mmHg}$ at $45 \mathrm{~min}$. Then picked up to 88 $\mathrm{mmHg}$ at $150 \mathrm{~min}$ remained same throughout the study. In group B, MAP from baseline 98.97 $\mathrm{mmHg}$ decreased to $87.90 \mathrm{mmHg}$ at $45 \mathrm{~min}$ then picking up slowly to $93.7 \mathrm{mmHg}$ at $120 \mathrm{~min}$ thereafter remained significantly high throughout the study period but the difference was not significant in both the groups $(\mathrm{P}>0.005)$.

The mean base line heart rate in group $\mathrm{A}$ which was $81 / \mathrm{min}$ reduced gradually to $79 / \mathrm{min}$ at $1 \mathrm{hr}$ and remained stable throughout the study. The mean baseline heart rate which was in group B $81 /$ min went up to $78 / \mathrm{min}$ at $60 \mathrm{~min}$ then significantly remained unchanged throughout the study which was comparable.

In another study done by Ozalp. G, Guner F, Kuru $\mathrm{N}$ et al on postoperative patient controlled epidural analgesia with opioid bupivacaine mixtures. After surgery patient complaining pain received loading doses of morphine $2 \mathrm{mg}$ (Group A) or fentanyl $50 \mu \mathrm{g}$ (Group B). For continuing pain, $1 \mathrm{mg}$ morphine in $4 \mathrm{ml}$ bupivacaine $0.125 \%$ $(0.25 \mathrm{mg} / \mathrm{ml}$ morphine and $1 \mathrm{mg} / \mathrm{ml}$ bupivacaine, Group A)or 20 micrograms fentanyl in $4 \mathrm{ml}$ bupivacaine $0.125 \%(5 \mu \mathrm{g} / \mathrm{ml}$ bupivacaine Group B). They concluded that fentanyl was hemodynamically stable with fewer side effects and excellent in providing postoperative analgesia which is close to our observation.

Side Effects: The four classic side effects of neuraxial opioids are Pruritus, Nausea and vomiting, Urinary retention and Depression of ventilation. Side effects are caused by the presence of drug either in CSF or systemic circulation. Most side effects are dose dependant.

The patients were observed for side effects like nausea and vomiting, sedation, urinary retention, pruritus and hypotension in both the groups. In our study 9 patients (30\%) developed nausea and 2 patients (10\%) had vomiting in group A and the group B only 2 patients (10\%) developed nausea with no vomiting.

Studies on postoperative pain relief between Epidural Fentanyl and buprenorphine by Hayashi H, Nishiuchi T, and Tamura H in 1993 showed that there was no difference between the analgesic efficacies, but incidence of nausea, vomiting and dizziness was significantly less in fentanyl compared to buprenorphine. 
Observations of study done by D. Kumar et aland Hayashi $\mathrm{H}$ et al also correlate with our study on Buprenorphine.

In our study Group B, 10 patients (33.3\%) developed pruritus compared to none in Group A. Studies done by SA Lytle et al. correlates with our study on fentanyl.

\section{Conclusion}

This study concludes that addition of buprenorphine to bupivacaine epidurally is better in providing prolonged and satisfactory postoperative analgesia compared to Fentanyl. though the incidence of nausea and vomiting was more in buprenorphine as compared to fentanyl group, which can be easily treated with antiemetics like Ondansetron.

\section{References}

1. Michael $\mathbf{J}$ Cousins. Neural blockade in clinical anesthesia and pain medicine. 4th ed. Philadelphia: Lippincott Williams and Wilkins; 2009.

2. Analgesia by epidural technique- Dolin $\mathrm{Sj}$, Cashman JNBland JM; 89: 4092002.

3. Combination of local anaesthetic and an opioid combination- Wheatley RG, Schugg Sa, Watson D; British Journal anaesth 87:47,2001.

4. J. W. Downing. BUPRENORPHINE: A new potent long-acting synthetic analgesic. Comparison with morphine.Br. J. Anaesth. (1977) 49 (3):251-255.

5. Inagaki Y, Mashimo $\mathrm{T}$, Yoshiya.Mode and site of analgesic action of epidural buprenorphine in humans. Anesth Analg. 1996 Sep;83(3):530-6.

6. Justins DM, Francis D, Houlton PG, Reynolds F. A controlled trial of extradural fentanyl in labour. $\mathrm{Br} \mathrm{J}$ Anaesth. 1982 Apr;54(4):409-14.

7. D'Angelo R, Gerancher JC, Eisenach JC, Raphael BL. Epidural fentanyl produces labor analgesia by a spinal mechanism. Anesthesiology. 1998 Jun;88(6):1519-23.
8. Grass JA. Fentanyl: clinical use as postoperative analgesic--epidural/ intrathecal route. J Pain Symptom Manage. 1992 Oct;7(7):419-30.

9. Christopher L Wu, Srinivasa N Raja. Treatment of post -operative pain. Lancet 2011;377:2215-25.

10. R.G.Wheatley, S.A.Schug, D. Watson. Safety and efficacy of postoperative analgesia. Br.JAnaesth 2001;87:47-61.

11. Mamatha Agarwal, Atulya Ratan. Evaluation of postoperative analgesic efficacy of extradural buprenorphine. Ind. Journal Anaesthesia 1998; 42:49-54.

12. Ichiishi $N$. et al; Effect of epidural Buprenorphine on post-operative respiratory function. Masui, 41(10) Oct: 1574-9, 1992.

13. Lt. Col. Y. Bhargav. Postoperative pain relief with Epidural Morphine and Buprenorphine. Indian journal of anaesthesia 1991; 39: 33.

14. Suraj.Dhale, Vaishali Shelgaonkar and V VAkulwar. A comparative study of epidural bupivacaine and epidural bupivacaine with fentanyl for peri operative analgesia. Indian journal anaesthesia 2000;44:35.

15. Zenz M., Pipen brock S., Hubner B., Glocke M: A double blind comparison of epidural Buprenorphine and epidural morphine in post-operative pain. AnaesthIntensive therapy - Notfallmed, 16(6): 3339, 1981.

16. Clinical actions of Fentanyl and Buprenorphine. The significance of receptor binding- Boas RA, Villiger JWBritish Journal Anaesth. 1985 Feb; 57 (2):192-6.

17. D.Kumar, Dev Gupta.Comparitive study of Epidural Buprenorphine and Ketamine for postoperative pain relief. Ind. Journal Anaesthesia1997; 41:38-49. 